\title{
Effects of Resource Depression on Use of Inexpensive and Escalated Aggressive Behavior: Experimental Tests Using Anna Hummingbirds
}

\author{
Paul W. Ewald ${ }^{1}$ and Gordon H. Orians ${ }^{2}$ \\ 1 Museum of Zoology, Division of Biology and Michigan Society of Fellows, University of Michigan, \\ Ann Arbor, Michigan 48109, USA \\ 2 Department of Zoology, University of Washington, Seattle, Washington 98195, USA
}

Received June 12, 1982 / Accepted December 10, 1982

Summary. To test whether alterations in aggressive behavior are responses to short-term resource depression, use of inexpensive and escalated territorial defense by Anna hummingbirds was analyzed as a function of the degree to which food could be depressed by foraging activities of territory owners and intruders. On depressible territories use of gorget display (a low cost defense) decreased and durations of chases increased as time since the previous feeding by owners increased. On nondepressible territories neither variable was significantly correlated with time since feeding. The percentage of intruders chased by owners was positively correlated with time since feeding on both depressible and nondepressible territories, but the magnitude of this trend decreased as food production increased. Departures from the territory tended to occur shortly after feeding on both types of territories, but this tendency was stronger on depressible territories.

When owners returned to their territories after long absences, gorget displays were used more frequently and chases were shorter than after short absences, but no significant change occurred in the percentage of intruders chased. These results suggest that owners respond to intruder-caused resource depression by altering their use of gorget display and durations of chases, but not their frequency of chases.

\section{Introduction}

Animals are often flexible in their aggressive behavior toward adversaries. Recent investigations of this subject predict and interpret levels of investment in aggressive behavior as functions of the adversary's behavior; the degree of escalation is assumed to depend on differences between adversaries in their estimates of payoffs from aggression and their relative fighting abilities (Maynard Smith and Price 1973; Parker 1974; Maynard Smith and Parker 1976). Although resource value is an important component of some current models of aggressive behavior (e.g. Parker 1974; Popp and DeVore 1978), the models do not analyze alterations of aggressive behavior as a function of the value of the contested resource. In the present paper we present and test hypotheses that consider use of inexpensive and escalated aggression as functions of the quality of the contested resource. This approach is complementary to current models and is potentially applicable to any agonistic encounter over depressible resources.

Fluctuations in the quality of a contested resource can result from extrinsic environmental variables or the activities of the animals themselves. Charnov et al. (1976) noted that short-term depression of food supply may be closely linked to territorial behavior. We propose a specific link: resource depression may influence the form of aggression because the form that yields the greatest net benefit depends on the level of resource abundance.

Changes in aggressive behavior in response to changes in food abundance have been especially well documented in nectarivorous birds. In response to day-to-day, experimental reductions in food production, territorial hummingbirds switch from chasing adversaries to low-cost displays and vocal threats (Ewald and Carpenter 1978). African sunbirds show similar responses (Frost and Frost 1980; Wilhelm et al. 1980). These results suggest that as territory quality decreases, the benefits from escalated aggression (better monopolization of food and deterrance of intruders from return visits) often drop below the costs (extra expendi- 
ture of energy and increased risk of injury), and, as a consequence, escalations occur less frequently.

Foraging by nectarivorous birds depresses nectar abundance over time scales of minutes to hours, with replenishment of nectar often beginning immediately after consumption. Based on the day-to-day territorial responses to changes in territory quality (Ewald and Carpenter 1978), we hypothesized that hummingbirds should increase their defense expenditures as food resources on the territory become replenished after a feeding. The first test of this hypothesis was presented by Ewald and Carpenter (1978): shortly after the owners fed they were less likely to chase intruders and more likely to depart from the territory than at later times.

One goal of the present study was to determine whether inexpensive aggressive acts are used less frequently as the time since an owner's previous feeding increases. We also sought to determine whether changes in territorial behavior are related to resource depression by intruders. Specifically, does an owner tend to use inexpensive territorial behavior more frequently after long absences from its territory than after short absences? (After long absences food abundance on territories tends to be depressed more strongly than after short absences because of the persistence of successful intruders.)

A third goal of this study was to determine whether short-term changes in territorial behavior are proximate responses to resource depression. To test this hypothesis (hereafter designated PRD) we compared territorial behavior on territories containing depressible food with that on territories containing nondepressible food. According to PRD, defense of nondepressible territories should not change in response to time since feeding. There are at least two plausible arguments for the null hypothesis, which states that the short-term shifts from inexpensive to expensive methods of territorial defense will occur on nondepressible as well as depressible territories.

First, digestive tracts of owners contain more food immediately after feeding than at later times. The net benefit of escalated chases might therefore be lower immediately after feeding than at later times because extra food in the digestive tract increases costs of flight and decreases maneuverability. Flight at these times might also hinder digestion.

Second, behavioral changes could be an inflexible, ultimate response to resource depression. In natural environments flowers visited by our subjects, adult male Anna hummingbirds (Calypte anna), are usually highly depressible (Stiles 1973); a proximate response to reduced depressibility may have failed to evolve because of insufficient selective pressure.

In addition to distinguishing between these hypotheses, our observations permitted investigation of the tendency for owners to depart shortly after feeding. If owners feed before departure to reduce losses to competitors and are able to evaluate residual food abundance after a foraging bout, then the change in tendency to depart as a function of time since feeding should be stronger on depressible territories than on nondepressible territories.

\section{Materials and Methods}

Observations of territorial behavior were made by P.W.E. and an assistant in Modjeska Canyon, Santa Ana Mtns., California, USA, during two study periods: 28 July through 19 August 1975 and 8 August through 12 September 1977. Observations from depressible and nondepressible territories were obtained during each year, being interspersed temporally to guard against potential seasonal effects. In 1975 we began recording data on nondepressible territories and ended on depressible territories. In 1977 we reversed this pattern.

The study site was located in riparian woodland, and was surrounded by both riparian woodland and chaparral. The only naturally occurring nectar sources in the immediate area were a few blossoms of tree tobacco (Nicotiana glauca), california fuchsia (Zauschneria californica) and scarlet monkey-flower (Mimulus cardinalis). These flowers provided a negligible fraction (much less than $0.1 \%$ ) of the total energy requirements of the local population of hummingbirds. The resident Anna hummingbirds do not migrate in late summer to areas containing more flowers, as they would normally do (Stiles 1973), because feeders are maintained at the site throughout the year.

To create depressible territories availability of food was controlled by using feeders with stopcocks (see Fig. $1 \mathrm{~b}$ in Ewald and Carpenter 1978). To create nondepressible territories we used conventional feeders (see Fig. 1 in Ewald and Rohwer 1980). Each territory contained only one feeder, which provided $0.6 \mathrm{M}$ sucrose solution. No other nectar-type food was available on any of the territories.

On depressible territories food was provided either continuously or in discrete units every $1 / 2 \mathrm{~h}$ from dawn until dusk. The discrete provisioning permitted a means of distinguishing between alternative hypotheses, as described in the Results section. The data from continuous provisioning permitted evaluation of the possibility that observed correlations resulted from the artificiality of discrete provisioning.

Data were gathered from four different birds on depressible territories and from five on nondepressible territories. The following activities were recorded on a per min basis: foraging bouts, durations of chases, timing of departures from territories, durations of absences, number of unchased intruders, number of chatter vocalizations, and number of intruders eliciting gorget display, an energetically inexpensive method of defense in which the owner moves its head from side to side while facing the intruder (more detailed descriptions of the gorget display are given by Ewald (1979), and also by Stiles (1982) who referred to the display as 'sway'). To quantify frequencies of chases and gorget displays, we calculated the percentage of intruders that elicited these responses from owners, 
excluding intrusions that occurred while the owners were absent.

When morphological characteristics were insufficient for identifying individuals, birds were marked by airborne-marking or perch-marking methods (see Ewald and Rohwer 1980).

When owners were absent for 1 min or longer, the time interval between their return and their next feeding was not included in analyses of territorial behavior as a function of time since feeding. These intervals were excluded because we expected that owners returning from a long absence would adjust their territorial behavior in a manner opposite to the predicted changes of a bird that remained on its territory after feeding (see Introduction).

To determine whether owners tended to feed prior to departing from the territory, frequencies of departure were calculated by dividing the number of departures by the number of minutes available for departure for each successive minute after feeding (see Ewald and Carpenter 1978).

To determine the statistical significance of correlations involving discrete variables (e.g., occurrence of gorget displays, chases and departures), we used Cochran's rank-ordered $\chi^{2}$-test (Cochran 1954; $1 d f$ ) for within treatment correlations and a $2 \times 2 \times 2$ median test for between treatment correlations. For continuous data we used Spearman rank-tests unless parametric tests were more apporpriate. Tests were two-tailed unless stated otherwise.

\section{Results}

\section{Form of Defense and Time Since Feeding}

No significant difference existed between discrete and continuous provisioning with respect to territorial behavior as a function of time since feeding ( $P>0.3$ for all comparisons). Data for these two treatments were therefore combined for the following analyses of territorial activity.

Owners of depressible territories reduced defense costs shortly after feeding by using gorget displays more frequently (Fig. $1 \mathrm{a}$ ), by chasing a lower percentage of intruders (Fig. $2 \mathrm{a}$ ) and by reducing durations of chases (Fig. $3 \mathrm{a}$ ).

Based on estimates of energy expenditure during flight (see Ewald and Rohwer 1980) and while perching (see Ewald and Carpenter 1978), depressible territories provided the following proportions of the owners' daily energy requirements per day: $0.3,0.4,0.6,0.8,1.0$ and 1.2 for discrete provisioning, and 0.4 for each of the three territories with continuous provisioning. Throughout this range, owners defended well-defined territories and nearly always drained their feeders by the end of each foraging bout; intruders obtained approximately $10 \%$ of the available food. Owners of the poorer territories obtained the remainder of their energy requirements by intruding on richer territories containing feeders, feeding on insects and feeding on the scanty, undefended flowers.

To make sure that the significant correlations in Fig. $1 \mathrm{a}, 2 \mathrm{a}$ and $3 \mathrm{a}$ were not statistical artifacts

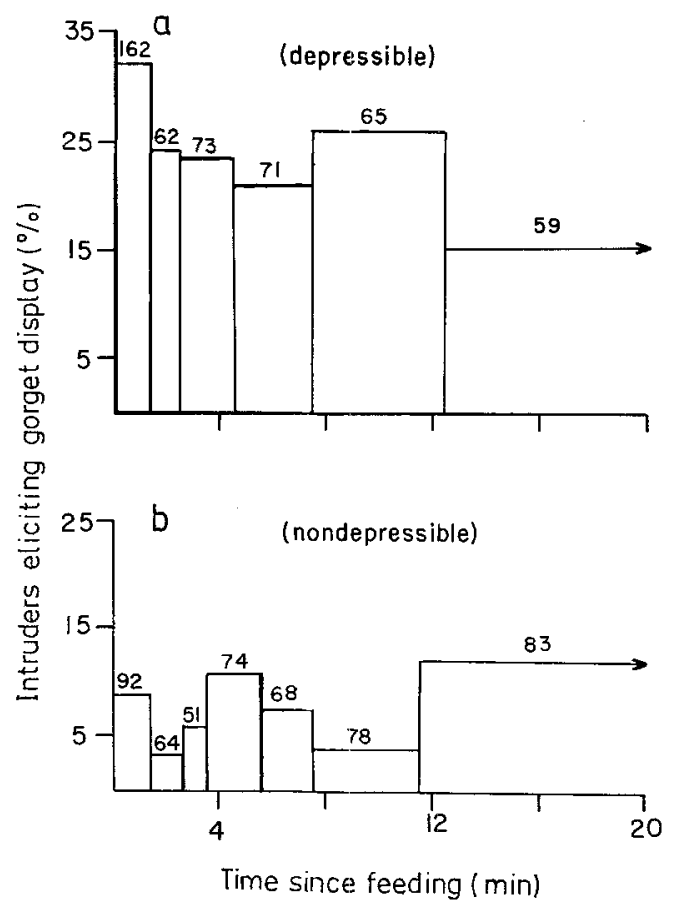

Fig. 1a, b. Percent of intruders eliciting gorget display from owners as a function of time since feeding. Intervals based on less than 50 intrusions were grouped with the smaller of the two adjacent intervals until all intervals were based on at least 50 intrusions. The number of intrusions that occurred in each interval is given above the histogram. a Depressible territories: one-tailed $P<0.01 ; \chi^{2}=5.5$. b Nondepressible territories: $P>$ $0.5 ; \chi^{2}=0.3$

that resulted from the grouping of different provisioning rates, data from each provisioning rate were divided in half according to the time since feeding of the median event. The value of the half soon after feeding was then subtracted from the more distant half, and these differences were tested using a one-tailed, matched pairs randomization test (Siegel 1956). In each case the differences were statistically significant (for the \% of intruders eliciting gorget display, $P=0.03$; for $\%$ of intruders chased, $P<0.01$; for duration of chases, $P=0.03$ ).

Use of gorget display by owners of nondepressible territories was not significantly correlated with time since feeding (Fig. 1 b), but the percentage of intruders chased was (Fig. 2b). Duration of chases was positively correlated with time since feeding, but this trend falls just short of statistical significance (Fig. 3b). This lack of statistical significance and the larger sample size on nondepressible territories (Fig. 3) suggests that the relationship between duration of chases and time since feeding is stronger on depressible territories than on nondepressible territories; however, the difference between these two histograms was not significantly 


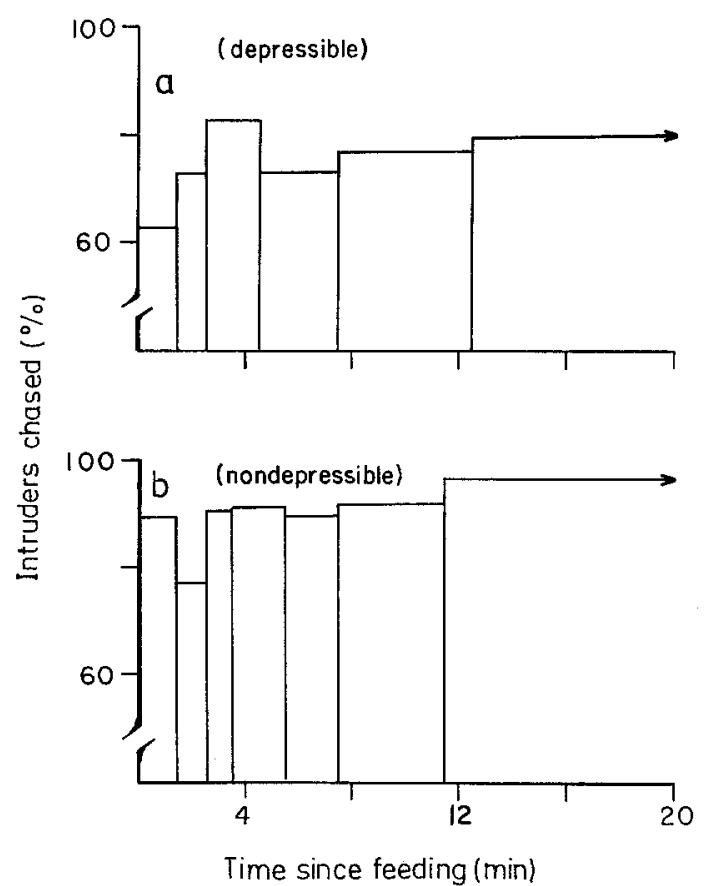

Fig. 2a, b. Percent of intruders chased by owners as a function of time since the owner last fed. Data were grouped as in Fig. 1. a Depressible territories: one-tailed $P<0.05 ; \chi^{2}=5.4$; the number of intrusions per interval are the same as in Fig. 1 a. This histogram and Fig. 4a include data presented by Ewald and Carpenter (1978) and data collected after that paper was written. b Nondepressible territories: one-tailed $P<0.01$; $\chi^{2}=7.0$; the number of intrusions per interval are the same as in Fig. $1 \mathrm{~b}$

different $\left(P>0.1, r_{s}=0.35, N=8\right.$ intervals). Similarly, the difference between Fig. $2 \mathrm{a}$ and $\mathrm{b}$ was not significant $\left(0.3<P<0.5, \chi^{*}=0.54\right)$, but the difference between Fig. $1 \mathrm{a}$ and $\mathrm{b}$ was statistically significant $\left(P<0.02, \chi^{2}=6.10\right)$. (Before running the two preceding tests, mean percentages of the two treatments in each test were equalized to eliminate any influence of differences in the means on the level of statistical significance.)

The range of discrete provisioning rates permitted a means of distinguishing the hypothesis based on digestive constraints (DC) from those based on proximate responses to resource depression (PRD) and inflexible ultimate responses to resource depression (IURD). According to DC, as provisioning rate increases the magnitude of the change in behavior (as a function of time since feeding) should increase because a greater load of food is gained per visit. According to PRD, a negative correlation, a positive correlation, or no correlation between provisioning rate and behavioral variables could occur depending on (i) the amount

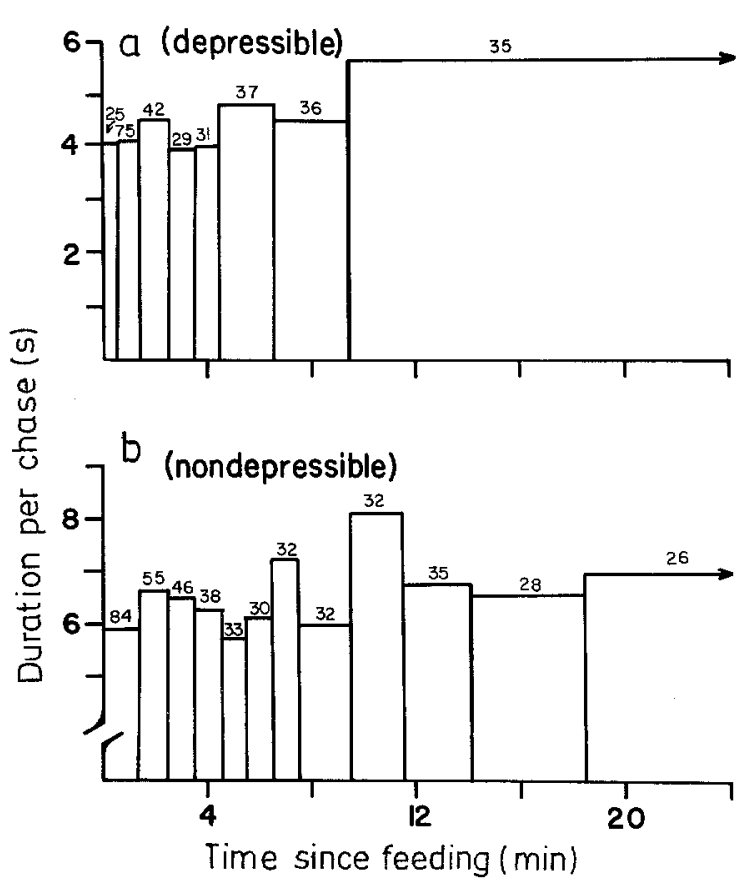

Fig. 3a, b. Mean durations of chases by owners as a function of time since feeding. Intervals based on less than 25 chases were grouped with the smaller of the two adjacent intervals until all intervals were based on at least 25 chases. We grouped by 25 instead of by 50 (as in Figs. 1 and 2) because the reduction in power due to small numbers of intervals is more severe for Spearman rank than for rank-ordered $\chi^{2}$. The number of chases that occurred in each interval (after grouping) are given above the histogram. a Depressible territories: one-tailed $P<0.05$; $r_{s}=0.68$. b Nondepressible territories: one-tailed $P<0.06 ; r_{s}=$ 0.58

of time since feeding before the variables reach their equilibrial levels and (ii) the difference between the equilibrial levels and the levels just after feeding. According to IURD, no correlation should occur.

For each of the behavioral variables in Figs. 1, 2 , and 3 , the magnitude of the changes in territorial behavior following feeding was negatively correlated with provisioning rate; thus, DC is not supported. For only one of these variables - the percentage of intruders chased - was the correlation significant $\left(P<0.05 ; r_{s}=-0.89\right.$ for discrete provisioning, and $r_{s}=-0.72$ for both methods of provisioning combined; including the data in Fig. 2 b as the tenth and richest provisioning rate increases the level of significance slightly, $r_{s}=-0.70$ ).

PRD interprets short-term adjustments in territorial behavior as direct responses to short-term depressions in food abundance. Alternatively, one could argue that these adjustments were a direct response to changes in intrusion rates which resulted from the short-term depression in food 


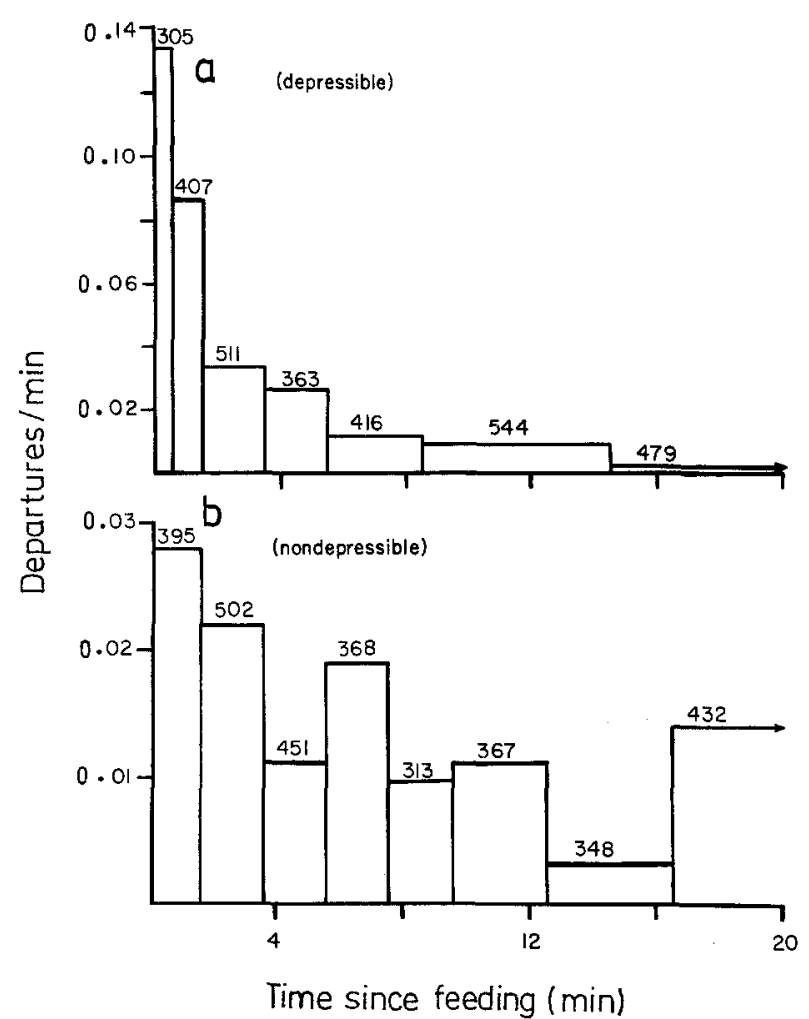

Fig. 4a, b. Departure frequency by territory owners as a function of time since feeding. To make sample sizes comparable, intervals with a data base of less than $300 \mathrm{~min}$ available for departure were grouped with the smaller of their two adjacent intervals until all intervals were based on at least $300 \mathrm{~min}$. Number of min available for departure in each interval (after grouping) are presented above the histogram. a Depressible territories: one-tailed $P \ll 0.001 \chi^{2}=113.9$. b Nondepressible territories: one-tailed $P<0.01 ; \chi^{2}=6.2$

abundance or the foraging activity of the owner (see Myers et al. 1979 for an analogous application of this argument); however, during out study intrusion rates were not correlated with time since feeding $\left(P \gg 0.1, r_{s}=-0.21\right.$, using time intervals of Fig. 4a).

To investigate further the tendency to use inexpensive aggression shortly after feeding, we computed the chase: chatter ratio for each time interval after feeding. The ratio measures the use of overt aggression relative to vocal threat. Although this ratio decreased as a function of extrinsic day-today changes in resource depression (Ewald and Carpenter 1978), it did not change significantly as a function of time since feeding $\left(P>0.7 ; \chi^{2}=0.1\right)$.

The tendency of owners to depart from their territories declined as time since feeding increased on both depressible and nondepressible territories (Fig. 4). Note, however, that the tendency for departures to occur shortly after feeding is more extreme on depressible territories $(P \ll 0.001$; $\left.\chi^{2}=33.8\right)$.

\section{Defense After Successful and Unsuccessful Feedings}

To distinguish DC from the resource depression hypotheses, changes in territorial behavior after consumption of discrete rations of food were compared with changes in behavior after feeding at an already drained feeder. According to DC the temporary shift to inexpensive defense after feeding should occur in response to feedings in which the half-hour ration of food was consumed, but not in response to feedings in which the feeder had not yet been filled with the next ration. In contrast, if the temporary shift to inexpensive defense was a response to feeding activity (i.e., IURD or PRD) then the shift should occur as a response to either kind of feeding.

Testing this idea is complicated by the sequential nature of successful and unsuccessful feedings: time intervals after an unsuccessful feeding are also time intervals after the previous successful feeding. Some changes in territorial behavior might therefore occur after unsuccessful feedings even if territorial behavior does not respond directly to the unsuccessful feedings. To reduce the influence of previous successful feedings on correlations between territorial behavior and time since an unsuccessful feeding, the following comparison included only unsuccessful feedings that occurred at least five minutes after a successful feeding. Beyond 5 min after feeding, territorial behavior changed little as a function of time since feeding (see Fig. $1 \mathrm{a}, 2 \mathrm{a}$ and $3 \mathrm{a}$ ).

DC predicts that changes in territorial behavior after such unsuccessful feedings should be weaker (if they occur at all) than analogous changes after successful feedings. To test this prediction a $2 \times 2 \times 2$ test was conducted at each rate of provisioning for discrete variables (i.e., intruders eliciting chases and gorget displays) and an ancova for chase durations. To eliminate the possibility of an owner obtaining food off of the territoriy, these comparisons included only intrusions for which the owner was continuously on his territory since his previous feeding. None of these comparisons yielded a difference that was near statistical significance, and the number of comparisons running counter to $\mathrm{DC}$ was equal to the number in the direction consistent with DC.

This test of DC assumes that the birds weigh substantially more after successful feedings than after unsuccessful feedings. If defecations tend to 
occur during such inter-feeding intervals, this assumption would be realistic. Information on time between defecations would, therefore, be useful in evaluating this assumption. On 3-4 September 1978 some relevant data were collected from an owner that remained in his territory for long periods of time without departing. By positioning observers within a few meters of the owner's perches all defecations within these periods were recorded. These data yield a mean interval between defecation of $10.1 \pm 10.6 \mathrm{~min}(N=16$ intervals $)$. The mean time interval between an unsuccessful feeding and the previous successful feeding was $19.2 \pm 7.9 \min (N=582$ intervals). The data on defecation are therefore consistent with the assumption described above.

\section{Form of Defense and Duration of Absence}

To determine whether owners increased their use of inexpensive methods of defense after long absences from depressible territories, we analysed the use of gorget displays and chases, and the durations of chases as functions of durations of absence. The percentage of intruders eliciting gorget display was positively correlated with the duration of absence (one-tailed $P<0.05 ; \chi^{2}=3.06$; mean duration of absence was $4.7 \pm 8.1 \mathrm{~min} ; N=$ 120 intrusions). After long absences (i.e., greater than $5 \mathrm{~min}$ ) chases were shorter than after short absences (i.e., less than $5 \mathrm{~min} ; 2.4$ vs $4.1 \mathrm{~s}$ per chase; one-tailed $P<0.01 ; t$-test; $N=71$ chases). The percentage of intruders chased decreased as duration of absence increased, but this trend was not statistically significant (one-tailed, $0.1<P<$ $0.15 ; \chi^{2}=1.27$ ). We could not make analogous comparisons on nondepressible territories because no absences on these territories lasted longer than $2 \min (N=101$ absences $)$.

The increased use of gorget display and decreased durations of chases after long absences justify separate treatment of intruders based on whether owners had been absent from the territory for substantial periods (see Methods). If all intruders are combined, the decreased use of gorget display with increasing time since feeding is weaker (one-tailed $P<0.02 ; \chi^{2}=4.54$; cf. Fig. 1 a) and the increased duration of chases with increasing time since feeding falls just short of statistical significance (one-tailed $P<0.06 ; r_{s}=0.57$; cf. Fig. $3 \mathrm{a}$ ).

\section{Discussion}

Our results show that owners of nondepressible territories switch from inexpensive to expensive methods of defense as time since feeding increases: they chase a greater percentage of intruders, use longer chases, and use gorget displays less frequently.

The comparisons of depressible territories with nondepressible territories permit several conclusions about the reasons for these correlations. The proximate response to resource depression hypothesis (PRD) is a viable explanation of the increasing percentage of intruders eliciting gorget display from owners of depressible territories as a function of time since feeding. The statistically significant correlation between percentage of intruders chased and time since feeding on nondepressible territories, and the lack of a statistically significant difference between depressible and nondepressible territories are consistent with an inflexible ultimate response to resource depression (IURD), but as mentioned below, some proximate responses are present. The observed durations of chases are not sufficient to distinguish between PRD and IURD, but the stronger correlation on depressible territories suggests that $\mathrm{PRD}$ is of some importance.

Comparisons of territorial behavior following successful feeding with that following unsuccessful feeding did not support the digestive constraints hypothesis (DC) as an explanation of the correlations between defense behavior and time since feeding. Based on this result and the failure to obtain increasing changes in territorial behavior with increasing productivity rates, we conclude that PRD and IURD are better explanations of the observed correlations than DC.

Although the relationship between the percentage of intruders chased and time since feeding on depressible territories did not differ significantly from that on nondepressible territories, the relationship did change significantly as a function of the rate of provisioning. This change is not consistent with DC or IURD, but is consistent with PRD; thus, although the relationship between the percentage of intruders chased and time since feeding shows some inflexibility at high resource levels as predicted by IURD, the relationship also shows a proximate response to resource levels when analyzed over a broad range of resource levels.

The tendency to depart sooner after feeding on depressible territories than on nondepressible territories is consistent with the idea that owners depress resources prior to departure to reduce losses to birds that intrude during their absence. However, this tendency is also consistent with an alternative hypothesis: owners may depart soon after feeding because of decreased foraging success 
in the territory. (If owners are still hungry after draining the feeders they may depart shortly after feeding to satiate their hunger by foraging off the territory.) This alternative hypothesis can at most explain only part of the results in Fig. 4 because it cannot account for the correlation on nondepressible territories.

Why do owners still tend to feed prior to departure when they own nondepressible territories? Pre-departure feedings could provide owners with a meal to fuel their metabolism while they are off the territory, but such a benefit is dubious because absences from nondepressible territories lasted less than 2 min. A more plausible explanation is that this tendency persists on nondepressible territories because under natural conditions some degree of feeding prior to departure is beneficial, and the birds therefore lack evolved responses appropriate to the artificial situation of nondepressible food.

The correlations between duration of absence and both use of gorget display and duration of chases suggest that owners are responding to depression by intruders, but further study is needed to determine whether these correlations result from PRD and/or IURD. It is even possible that DC could yield these correlations, if food consumption while off the territory makes owners heavier after long absences than after short absences.

Our results coupled with those of earlier studies (Ewald and Carpenter 1978; Frost and Frost 1980; Wilhelm et al. 1980) exemplify how aggressive behavior of nectarivores responds to foraging activity and extrinsic influences on food abundance. Yet, even when resource levels are held constant, both inexpensive and escalated interactions occur. We therefore conclude that resource levels influence mean levels of inexpensive and escalated aggression, while variables such as payoff asymmetries, strategies of adversaries, and differences in fighting ability (see Maynard Smith and Parker 1986) probably contribute to the variation in aggressive responses observed at any given level of resource abundance. Similar responses are feasible in any system in which resources are defensible, depressible and assessible.

Acknowledgements. We thank S. Rohwer, W.J. Erckman, H. Markl and T.W. Schoener for helpful suggestions and criticism. R. Munson and B. Thomas provided generous use of facilities at Tucker Wildlife Sanctuary. R.T. Ray and L. Shemshedinofski aided in collection and reduction of data. Research was supported by grants from the National Science Foundation (DEB 77-15521), the Chapman fund of the American Museum of Natural History, the Orange County chapter of the Audubon Society and the Harry Frank Guggenheim Foundation.

\section{References}

Charnov ER, Orians GH, Hyatt K (1976) Ecological implications of resource depression. Am Nat 110:247-259

Ewald PW (1979) The hummingbird and the calorie. Nat Hist 88(8):92-98

Ewald PW, Carpenter FL (1978) Territorial responses to energy manipulations in the Anna hummingbird. Oecologia (Berl) $31: 277-292$

Ewald PW, Rohwer S (1980) Age, coloration and dominance in nonbreeding hummingbirds: a test of the asymmetry hypothesis. Behav Ecol Sociobiol 7:273-279

Frost SK, Frost PGH (1980) Territoriality and changes in resource use by sunbirds at Leonotis leonurus (Labiatae). Oecologia (Berl) 45:109-116

Maynard Smith J, Parker GA (1976) The logic of asymmetric contests. Anim Behav 24:159-175

Maynard Smith J, Price GR (1973) The Iogic of animal conflict. Nature 246:15-18

Myers JP, Connors PG, Pitelka FA (1979) Territory size in wintering sanderlings: the effects of prey abundance and intruder density. Auk 96:551-561

Parker GA (1974) Assessment strategy and the evolution of fighting behavior. I Theor Biol 47:223-243

Popp JL, DeVore I (1978) Aggressive competition and social dominance theory. In: Hamburg DA, McCown ER (eds) Perspectives in human evolution, vol 5, The great apes. Benjamin/Cummings, Menlo Park (California), pp 317-338

Siegel S (1956) Nonparametric statistics for the behavioral sciences. McGraw-Hill, New York

Stiles FG (1973) Food supply and the annual cycle of the Anna hummingbird. Univ Calif Publ Zool 97:1-109

Stiles FG (1982) Aggressive and courtship displays of the male Anna's hummingbird. Condor 84:208-225

Wilhelm K, Comtesse H, Pflum W (1980) Zur Abhängigkeit des Gesangs vom Nahrungsangebot beim Gelbbauchnektarvogel (Nectarinia venusta). Z Tierpsychol 54:185-202 